\title{
Targeting Cavity-Creating p53 Cancer Mutations with Small- Molecule Stabilizers: the Y220X Paradigm
}

\author{
Matthias R. Bauer," Andreas Krämer, "Giovanni Settanni, Rhiannon N. Jones, Xiaomin Ni, \\ Raysa Khan Tareque, Alan R. Fersht, John Spencer, and Andreas C. Joerger*
}

Cite This: ACS Chem. Biol. 2020, 15, 657-668

Read Online

\section{ACCESS |}

Џlll Metrics \& More

Article Recommendations

Supporting Information

ABSTRACT: We have previously shown that the thermolabile, cavity-creating p53 cancer mutant Y220C can be reactivated by small-molecule stabilizers. In our ongoing efforts to unearth druggable variants of the p53 mutome, we have now analyzed the effects of other cancer-associated mutations at codon 220 on the structure, stability, and dynamics of the p53 DNA-binding domain (DBD). We found that the oncogenic $\mathrm{Y} 220 \mathrm{H}, \mathrm{Y} 220 \mathrm{~N}$, and Y220S mutations are also highly destabilizing, suggesting that they are largely unfolded under physiological conditions. A high-resolution crystal structure of the Y220S mutant DBD revealed a mutation-induced surface crevice similar to that of Y220C, whereas the corresponding pocket's accessibility to small molecules was blocked in the structure of the $\mathrm{Y} 220 \mathrm{H}$ mutant. Accordingly, a series of carbazole-based small molecules, designed for stabilizing the Y220C mutant, also bound to and stabilized the folded state of the Y220S mutant, albeit with varying affinities due to structural differences in the binding pocket of the two mutants. Some of the

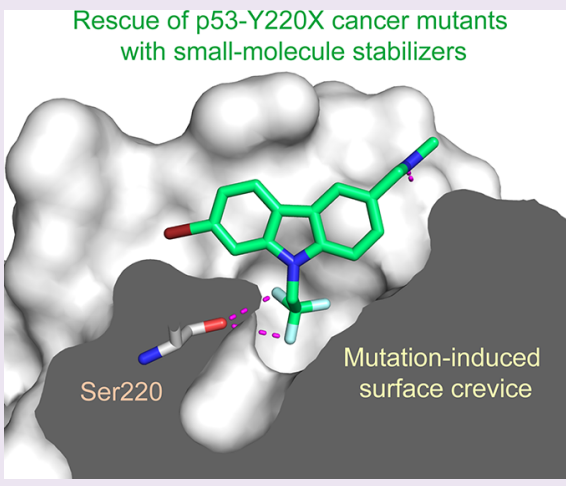
compounds also bound to and stabilized the Y220N mutant, but not the Y220H mutant. Our data validate the Y220S and Y220N mutants as druggable targets and provide a framework for the design of Y220S or Y220N-specific compounds as well as compounds with dual Y220C/Y220S specificity for use in personalized cancer therapy.

\section{INTRODUCTION}

The tumor suppressor $\mathrm{p} 53$ is inactivated by mutation in about half of all tumors, making mutant $\mathrm{p} 53$ a prime target for cancer therapy. $^{1-3}$ Most oncogenic p53 mutations are missense mutations mapping to its DNA-binding domain (DBD), yet the functional spectrum of these mutations is very diverse, depending on the distinct nature of each mutant protein. ${ }^{3-6}$ Nevertheless, despite this functional heterogeneity, mechanistically, the mutations can be broadly divided into DNA-contact mutations that remove an essential DNA contact, which prevents $\mathrm{p} 53$ from binding to its target promoters, and structural mutations. The latter lower the thermostability of the intrinsically unstable p53 protein to varying degrees, causing it to rapidly unfold and aggregate under physiological conditions. $^{7,8}$ An estimated one-third of common p53 cancer mutants are temperature-sensitive structural mutants that exhibit a loss of function under physiological conditions but retain at least some degree of transcriptional activity when assayed at low (permissive) temperatures, where they adopt a wild-type like conformation. ${ }^{4,7}$ It may, therefore, be possible to restore the function of this subset of cancer mutants with chemical chaperones. The Y220C mutation is an excellent paradigm for this rescue strategy. ${ }^{1}$ It is the ninth most frequent p53 cancer mutation and accounts for an estimated 100000 new cancer cases each year. We have previously shown that this highly destabilizing mutation creates an extended surface crevice that can be targeted by stabilizing small molecules (Figure 1). ${ }^{10}$ Using fragment-based screening and structurebased design, we have developed several chemically diverse classes of small molecules that bind to this pocket, increase the melting temperature, and hence stabilize and slow down the rate of aggregation of the mutant. ${ }^{11-17}$ Importantly, some of those molecules are biologically active in cancer cells with homozygous Y220C mutation and induce mutant-specific transcription of a series of $\mathrm{p} 53$ target genes, ${ }^{17-19}$ providing the proof-of-concept that pharmacological rescue of thermolabile cancer mutants with molecular chaperones is a viable and promising strategy. In addition, molecular dynamics simulations suggest that it might be possible to target other, transiently open pockets on the DBD surface. ${ }^{20,21}$ Alternative mutant p53 rescue strategies use thiol modifying alkylating agents, such as PRIMA-1 ${ }^{\text {Met }}$ (APR-246) $)^{22,23}$ and sulfonylpyrimidines, ${ }^{24}$ which have been shown to selectively kill cancer cells with compromised p53. In addition, metallochaperones have been developed for the rescue of the zinc-binding deficient $\mathrm{R} 175 \mathrm{H}$ mutant by increasing cellular zinc levels. ${ }^{25}$

Received: September 19, 2019

Accepted: January 28, 2020

Published: January 28, 2020 


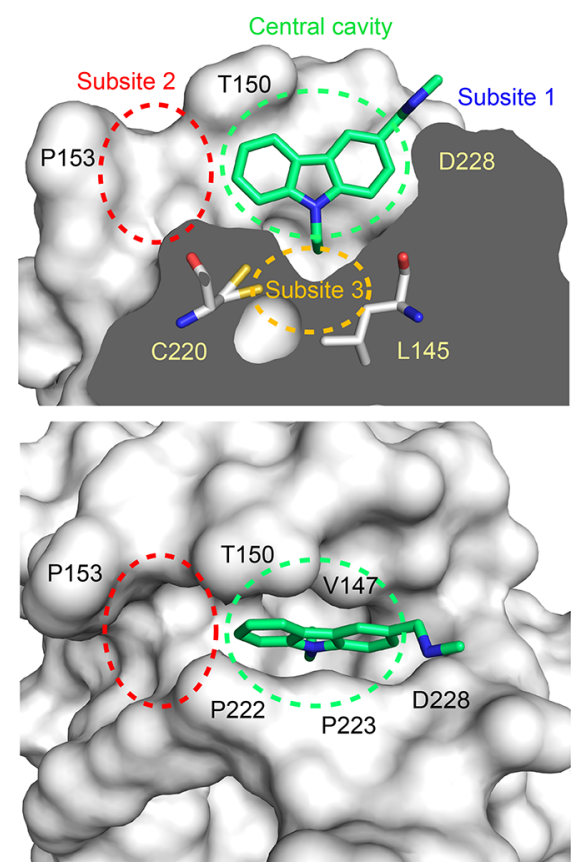

Figure 1. Mutation-induced surface crevice in the p 53 cancer mutant Y220C with bound molecule PK083. The mutant protein is shown as a surface representation in two different orientations: cross section of the mutation-induced surface crevice and top view. Bound carbazolebased stabilizer PK083 is shown as a stick model (PDB ID: 2VUK). Specific regions of the pocket that are discussed in this manuscript are highlighted. Adapted with permission from Bauer et al. Copyright 2019 Future Science Ltd. $^{17}$

These examples illustrate that different reactivation strategies are needed, depending on the underlying mechanism of inactivation. No single mutant is found at a frequency of $>6 \%$, and the 10 most frequent and most commonly studied "hotspot" mutants, including the Y220C mutant, together comprise only $<25 \%$ of all p53 mutations in total. ${ }^{26,27}$ Although this translates into a staggering 2.5 million new cancer cases per year, the vast majority of cancer patients have nonhotspot mutations with currently largely unknown structural and functional impact.

In our ongoing efforts to structurally characterize the p53 mutome and devise appropriate reactivation strategies, we have now analyzed the effects of other frequently occurring oncogenic mutations at codon 220 on the structure, stability, and dynamics of the p53 DBD. These data show that the oncogenic Y220S and Y220N mutations are also highly destabilizing, even more so than the Y220C mutant, and, like the Y220C mutant, create a unique extended surface crevice that can be specifically targeted by small-molecule stabilizers.

\section{RESULTS AND DISCUSSION}

Analysis of Cancer Mutation Frequencies at p53 Codon 220. The TP53 mutation database ${ }^{26}$ of the International Agency for Research on Cancer lists 402 cancer cases with a somatic Y220C mutation (Table 1). On the basis of the total number of reported p53 cancer mutations in the database, an overall p53 mutation rate in cancer of about $50 \%$, and a total number of 18 million new cancer cases worldwide in $2018{ }^{28}$ this mutation currently accounts for about 125000 new cancer cases each year, and its tendency is rising. There are also three other mutations at codon 220 that occur with an
Table 1. Frequency of p53 Cancer Mutations at Codon 220

$\begin{array}{ccc}\text { mutation } & \text { somatic } \text { count }^{a} & \text { germline count }^{a} \\ \text { Y220C } & 402 & 17 \\ \text { Y220H } & 20 & 0 \\ \text { Y220N } & 18 & 0 \\ \text { Y220S } & 17 & 3 \\ \text { Y220D } & 4 & 0 \\ \text { Y220F } & 1 & 0\end{array}$

${ }^{a}$ Number of cases in release R20 of the TP53 mutation database of the International Agency for Research on Cancer. ${ }^{26} N=28866$ for the somatic and $N=1245$ for the germline data set.

appreciable frequency in the database: $\mathrm{Y} 220 \mathrm{H}, \mathrm{Y} 220 \mathrm{~N}$, and Y220S (20, 18, and 17 cases, respectively). As with the Y220C mutation, these mutations are found across different types of cancer, including breast, lung, and liver cancer. Applying the same estimate as for the Y220C mutation, this translates to around 5000-6000 new cancer cases per year worldwide that are caused by each of these mutations. Interestingly, the Y220S mutation is also reported in three cases of familial cancer and has been associated with oncogenic gain of function, including angiogenesis induction and doxorubicin resistance. ${ }^{29}$ Two other mutations, Y220D and Y220F, are found in tumors, albeit very rarely. The Y220F mutation is reported only once in the database and is most likely a passenger rather than a driver mutation.

Effect of Y220X Cancer Mutations on the Thermostability of the DBD. We determined the effect of the four most frequent Y220X cancer mutations on the thermostability of the DBD by differential scanning fluorimetry (DSF). The mutations were introduced in a superstable variant of the $\mathrm{p} 53$ DBD (M133L/V203A/N239Y/N268), ${ }^{30,31}$ which has been successfully used previously for structural studies of conformationally unstable p53 cancer mutants. ${ }^{10,32}$ All four mutations were highly destabilizing (Table 2). The $\mathrm{Y} 220 \mathrm{H}$ and Y220C

Table 2. Melting Temperatures of p53-Y220X Mutant DBDs

$\begin{array}{ccc}{\text { codon } 220 \text { mutation }^{a}}^{a} & T_{\mathrm{m}}\left({ }^{\circ} \mathrm{C}\right)^{a} & \Delta T_{\mathrm{m}}\left({ }^{\circ} \mathrm{C}\right)^{b} \\ \text { WT residue } & 51.5 \pm 0.1 & \\ \text { Y220H } & 45.1 \pm 0.1 & -6.4 \\ \text { Y220C } & 43.7 \pm 0.1 & -7.8 \\ \text { Y220N } & 39.9 \pm 0.2 & -11.6 \\ \text { Y220S } & 39.4 \pm 0.2 & -12.1\end{array}$

${ }^{a}$ Melting temperatures of Y220X mutants were measured in the framework of a stabilized quadruple mutant DBD (M133L/V203A/ $\mathrm{N} 239 \mathrm{Y} / \mathrm{N} 268 \mathrm{D})$. The $T_{\mathrm{m}}$ of the wild-type DBD is $\sim 45{ }^{\circ} \mathrm{C} . .^{32,57}$ Quadruplicate measurements, mean \pm SEM is given. ${ }^{b} \Delta T_{\mathrm{m}}=T_{\mathrm{m}}$ (mutant) $-T_{\mathrm{m}}$ (wild type)

mutations lowered the $T_{\mathrm{m}}$ of the DBD by about 6 and $8{ }^{\circ} \mathrm{C}$, respectively. The other two mutations, Y220S and Y220N, were even more destabilizing, lowering the $T_{\mathrm{m}}$ by $\sim 12{ }^{\circ} \mathrm{C}$. This dramatic stability loss suggests that all four p53-Y220X cancer mutants are largely unfolded under physiological conditions in cancer cells, as shown previously for the Y220C mutant. ${ }^{18} \mathrm{It}$ will, therefore, be interesting to explore whether the more deleterious effect of the Y220S and Y220N mutations on protein stability compared with $\mathrm{Y} 220 \mathrm{C}$ and $\mathrm{Y} 220 \mathrm{H}$ is also associated with a more severe phenotype.

Structures of the Y220S, Y220N, and Y220H Mutants. We determined crystal structures of the $\mathrm{Y} 220 \mathrm{H}$ and $\mathrm{Y} 220 \mathrm{~S}$ mutant at a resolution of 1.44 and $1.50 \AA$, respectively. The 
A

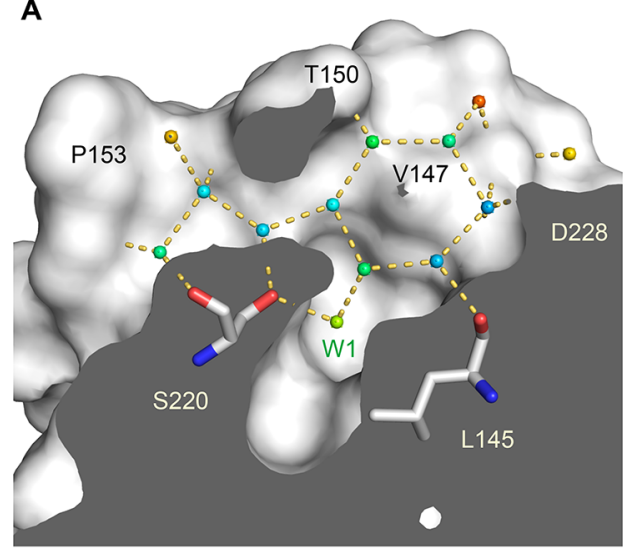

B

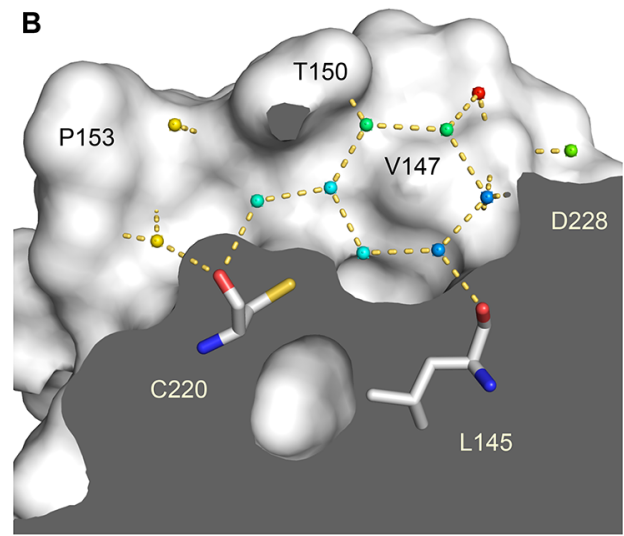

C

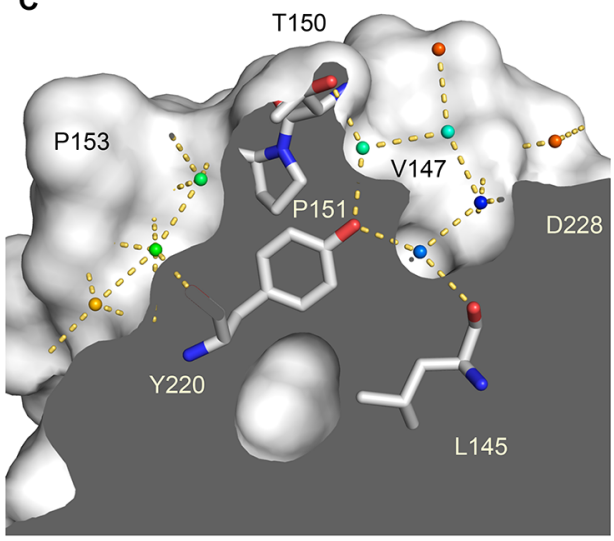

D

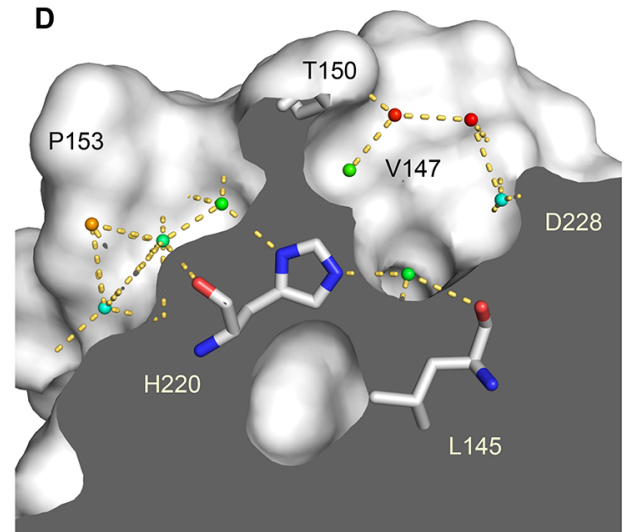

Figure 2. Structures of the Y220X mutants. Molecular surface representation of a cross-section of the mutation-induced surface crevice in mutants Y220S (A) and Y220C (B). Water molecules bound inside the pocket are shown as small spheres and color-coded according to their crystallographic thermal factors (B factors) in a rainbow gradient from blue (B factor $=10 \AA^{2}$ ) to red $\left(\mathrm{B}\right.$ factor $\left.=50 \AA^{2}\right)$. Water-mediated hydrogen bonds are highlighted with orange dashed lines. Selected side chains in the pocket are highlighted as stick models. (C) The equivalent cross-section of the wild-type structure (PDB ID 1UOL) shows that Tyr220 prevents formation of an extended surface crevice and effectively separates two smaller, pre-existing subpockets. (D) In the structure of the $\mathrm{Y} 220 \mathrm{H}$ mutant, the histidine side chain overlays with the position of the Tyr side chain in the wild type, which also blocks the binding pocket. All structures were determined in the same space group, and chain A of the asymmetric unit is shown.

crystals used for structure solution were isomorphous to those obtained previously for the Y220C mutant and the stabilized wild-type DBD and contained two molecules in the asymmetric unit. We also collected additional X-ray data for the Y220C mutant, extending the resolution from $1.65 \AA$ (PDB entry 2J1X) to $1.24 \AA$. The overall structure of the wild-type DBD and its key functional motifs are conserved in the Y220S and $\mathrm{Y} 220 \mathrm{H}$ mutants. The Y220S mutant structure, however, also revealed a mutation-induced cavity similar to that observed for the Y220C mutation. In both cases, the largeto-small substitution at residue 220 connects two pre-existing smaller cavities, resulting in an extended surface crevice. A cross-section of the cavity in both mutants is shown in Figure 2, highlighting the conserved water network in both mutant structures. Despite the overall similarity in shape, there are distinct differences. As a result of the smaller, more polar side chain in the Y220S mutant, the subsite-3 region at the bottom of the pocket is slightly deeper and more polar (see Figure 1 for the location and numbering of different subpockets). This is reflected in the incorporation of an additional, weakly bound water molecule that interacts with the hydroxyl group of Ser220 (Water W1 in Figure 2A). We have previously shown that the shape of subsite 3 is modulated by the conformational state of Cys220. ${ }^{13}$ In some of the Y220C-ligand complexes, but not in the apo structure, the side chain of Cys 220 is flipped, with the sulfhydryl group pointing away from the cavity toward a hydrophobic patch formed by the side chains of Leu145, Val157, and Leu257, which increases the depth of the binding pocket. Fluctuation between these alternative states of the Y220C pocket has also been seen in MD simulations. ${ }^{13}$ In the case of the Y220S mutant, an equivalent flip of the serine side chain would be energetically unfavorable, leaving the hydroxyl group in a hydrophobic environment and impeding $\mathrm{H}$-bond formation with solvent molecules in the pocket. At the upper rim of the binding pocket, the side chains of Thr150 and Pro222 contact each other. This is also observed in some Y220C mutant structures, whereas in other structures, Pro222 is further away and the pocket thereby more open, allowing access of small-molecule binders. ${ }^{13,15}$

In the crystal structure of the $\mathrm{Y} 220 \mathrm{H}$ mutant, the imidazole ring of the His220 side chain roughly superimposes with the position of the tyrosine aromatic ring in the wild-type structure (Figure 2C,D), thereby effectively blocking the binding pocket seen in the other Y220X cancer mutant structures. Both imidazole nitrogen atoms form a hydrogen bond with a structural water molecule. The partial retention of Tyr220mediated interactions in the wild type is reflected in the less 
A

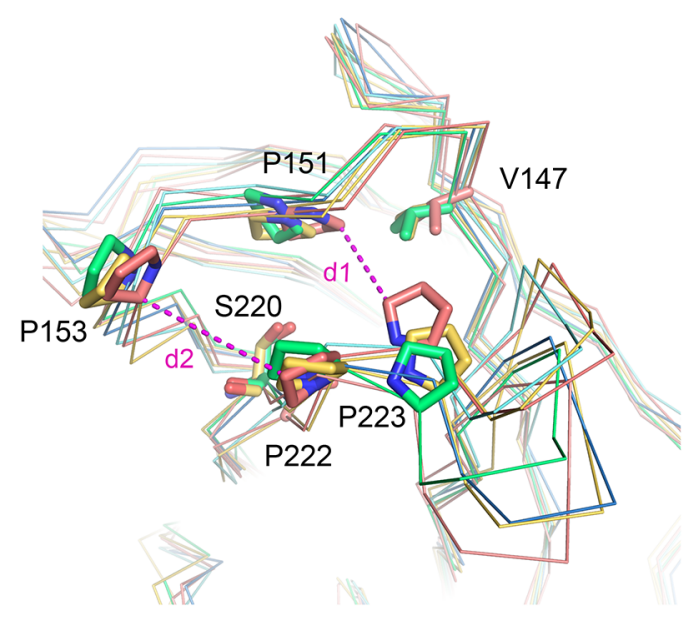

B

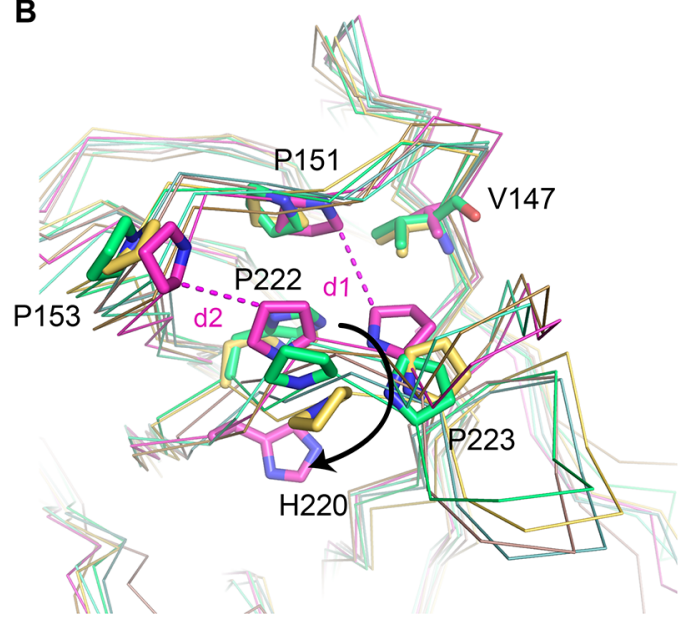

C

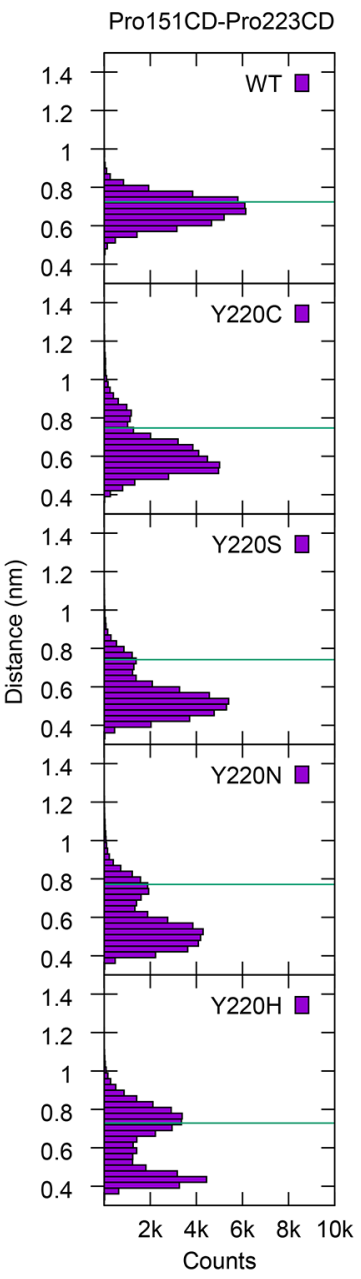

Pro153CA-Pro222CG

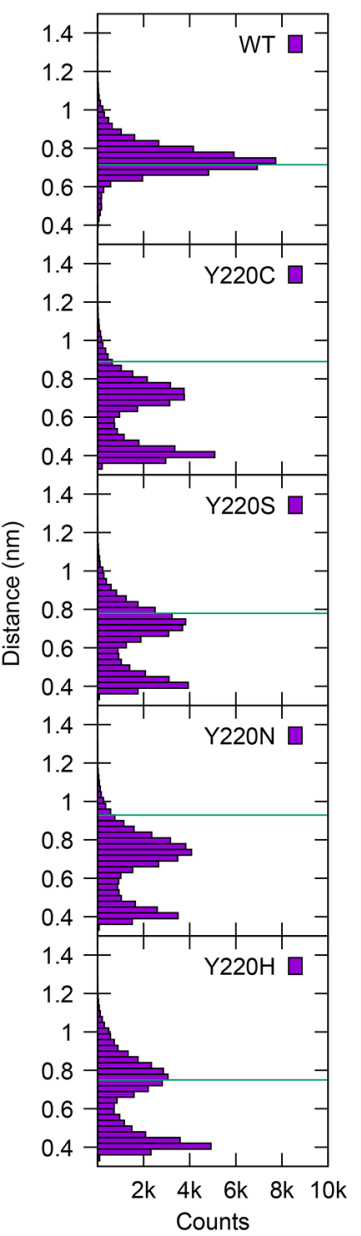

Figure 3. MD simulations of Y220X mutants showing open and closed states of the pocket region. (A) Superposition of C $\alpha$ traces of the crystal structure of the Y220S mutant (green) and three representative structures of open and closed states along the trajectory. Selected side chains are shown as stick models. Selected distances across the central cavity (d1) and subsite 2 (d2) are highlighted with magenta dashed lines. (B) Superposition of $\mathrm{C} \alpha$ traces of the crystal structure of the $\mathrm{Y} 220 \mathrm{H}$ mutant (green) and three representative structures of open and closed states along the trajectory. The view is the same as in panel A. Concerted collapse of the pocket region is associated with His 220 swinging out of the pocket. (C) Distribution of representative distances shows that the Y220X mutants visit open and closed states during the simulations, whereas the wild type stays close to the conformation of the crystal structure. The distance between the $\mathrm{C} \delta$ atoms of Pro151 and Pro223 (left) is a measure for the width of the central cavity, whereas the distance between the $\mathrm{C} \alpha$ atom of Pro153 and the $\mathrm{C} \gamma$ of Pro222 spans subsite 2. The green line indicates the distance in the corresponding crystal structures (chain A) or the starting model in case of the Y220N mutant.

severe stability loss compared with the other Y220X mutants tested.

For the Y220N mutant, only poorly diffracting crystals were obtained; hence the structure of this mutant was modeled with the SWISS-MODEL ${ }^{33}$ server using the Y220C mutant structure as a template. According to this model, the Y220N mutation also creates an extended surface crevice, but the center of the pocket is not as deep as in the Y220C and Y220S mutants and more polar (Supporting Information Figure S1).

Dynamics of the Y220X Surface Crevice. We performed molecular dynamics (MD) simulations on the different p53 DBD variants to provide insights into the structural plasticity of the mutation-induced binding pocket. The stabilized pseudo wild type and the four Y220X mutants of this scaffold were simulated using atomistic MD, each for a total of $800 \mathrm{~ns}$ (see Methods for details) under physiological conditions and in the absence of any stabilizing ligand (only the zinc atom was retained). During the simulated time, none of the mutants underwent unfolding, although specific fluctuations around the
X-ray conformation were observed, revealing the dynamics of the systems. The fluctuations of the proteins around their average structure, measured as $\mathrm{C} \alpha$ root-mean-square fluctuations (RMSF) of residues 97-289, ranked them according to their experimentally determined stability, as seen for other model systems, ${ }^{34}$ i.e., the lower the thermostability of the mutant, the higher the average RMSF in the simulations (Table S1). The profile of the RMSF (Supporting Information Figure S2) shows enhanced fluctuations of all the Y220X mutants around the binding pocket (residue 145-157 and 218-232) compared with the wild type, which was expected, given that they lack the Tyr side chain that holds the S3/S4 and S7/S8 loops together. The distributions of the distances between the $\mathrm{C} \delta$ atoms of Pro151 and Pro223 (d1) and between the $\mathrm{C} \alpha$ atom of Pro153 and the $\mathrm{C} \gamma$ atom of Pro222 (d2), which line the pocket, are bimodal for the mutants (but not for the wild type), hinting at the presence of open and closed conformations of the pocket in the Y220X mutants (Figure 3). The first distance is a measure for the opening/ 
Table 3. Thermostabilization and Dissociation Constants of Carbazole-Based Y220S and Y220C Binders

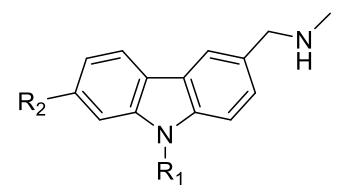

\begin{tabular}{|c|c|c|c|c|c|c|}
\hline \multirow[b]{2}{*}{ Compound } & \multirow[b]{2}{*}{$\mathrm{R}_{1}$} & \multirow[b]{2}{*}{$\mathrm{R}_{2}$} & \multicolumn{2}{|c|}{ Y220S mutant } & \multicolumn{2}{|c|}{ Y220C mutant } \\
\hline & & & $\Delta T_{\mathrm{m}}\left({ }^{\circ} \mathrm{C}\right)^{\mathrm{a}}$ & $K_{\mathrm{d}}(\mu \mathrm{M})$ & $\Delta T_{\mathrm{m}}\left({ }^{\circ} \mathrm{C}\right)^{\mathrm{a}}$ & $K_{\mathrm{d}}(\mu \mathrm{M})$ \\
\hline PK083 & $\mathrm{CH}_{2} \mathrm{CH}_{3}$ & $\mathrm{H}$ & $0.7 \pm 0.1$ & - & $1.0 \pm 0.1$ & $125 \pm 10^{b}$ \\
\hline PK9284 & $\mathrm{CH}_{2} \mathrm{CH}_{3}$ & $\mathrm{Br}$ & $1.8 \pm 0.1$ & - & $2.4 \pm 0.1$ & $14 \pm 2^{b}$ \\
\hline PK9295 & $\mathrm{CH}_{2} \mathrm{CH}_{3}$ & & $0.9 \pm 0.0$ & - & $1.2 \pm 0.1$ & $62 \pm 7^{b}$ \\
\hline PK9318 & $\mathrm{CH}_{2} \mathrm{CH}_{3}$ & & $2.1 \pm 0.0$ & - & $4.4 \pm 0.1$ & $2.6 \pm 0.4^{b}$ \\
\hline PK9320 & $\mathrm{CH}_{2} \mathrm{CH}_{3}$ & & $1.8 \pm 0.1$ & - & $3.4 \pm 0.0$ & $4.1 \pm 0.2^{b}$ \\
\hline PK9322 & $\mathrm{CH}_{2} \mathrm{CH}_{3}$ & & $3.0 \pm 0.0$ & - & $3.4 \pm 0.0$ & $8.3 \pm 2.6^{b}$ \\
\hline PK9323 & $\mathrm{CH}_{2} \mathrm{CH}_{3}$ & & $3.7 \pm 0.3$ & $5.9 \pm 1.3$ & $3.1 \pm 0.1$ & $5.3 \pm 1.4^{b}$ \\
\hline PK9424 & $\mathrm{CH}_{2} \mathrm{CH}_{3}$ & & $1.2 \pm 0.1$ & - & $2.3 \pm 0.1$ & - \\
\hline PK9327 & $\mathrm{CH}_{2} \mathrm{CH}_{3}$ & & $1.2 \pm 0.0$ & - & $3.7 \pm 0.2$ & - \\
\hline PK9328 & $\mathrm{CH}_{2} \mathrm{CH}_{3}$ & & $1.5 \pm 0.1$ & - & $3.7 \pm 0.0$ & $1.7 \pm 0.2^{b}$ \\
\hline PK9331 & $\mathrm{CH}_{2} \mathrm{CH}_{3}$ & & $1.1 \pm 0.1$ & - & $2.1 \pm 0.1$ & - \\
\hline PK9255 & $\mathrm{CH}_{2} \mathrm{CF}_{3}$ & $\mathrm{H}$ & $3.2 \pm 0.0$ & $16 \pm 2$ & $1.7 \pm 0.1$ & $28^{c}$ \\
\hline PK9301 & $\mathrm{CH}_{2} \mathrm{CF}_{3}$ & $\mathrm{Br}$ & $5.1 \pm 0.1$ & $4.0 \pm 1.0$ & $3.5 \pm 0.1$ & $6.0 \pm 0.3$ \\
\hline
\end{tabular}

${ }^{a}$ Measured at a compound concentration of $250 \mu \mathrm{M}$. Mean values of quadruplicate measurements \pm SEM are shown. ${ }^{b}$ Data taken from Bauer $e t$ al. ${ }^{17}{ }^{c}$ Data taken from Bauer et al. ${ }^{14}$

collapse of the central part of the pocket, whereas the second distance describes the expanse of subsite 2 . The time series of these distances shows that open and collapsed conformations are visited repeatedly during the simulations (Supporting Information Figures S3 and S4). Cluster analysis of the side chains of the residues around the pocket $(109,145-157,218-$ 232,257 ) was used to extract representative conformations of the open and collapsed state of the central cavity. In the closed state, as shown for the Y220S mutant (Figure 3A), Pro153 collapses into the pocket and packs against the side chain of Val147 and Pro151 on the other side of the pocket. Y220H, the most thermostable of the four Y220X mutants, which incidentally also has the smallest pocket, had the smallest population of this state. In the $\mathrm{Y} 220 \mathrm{H}$ simulations, collapse of Pro223 into the pocket is linked to a displacement of the His220 side chain, which swings out of the pocket, thereby facilitating its collapse (Figure $3 \mathrm{~B}$ ). Subsite 2 was generally less prone to collapse than the central pocket in the simulations. There was also an interesting difference in the coupling between the two subsites in the various mutants. An open state of the central pocket in the Y220S and Y220C mutants was generally linked to an open state of subsite 2 , but collapse of the central pocket did not necessitate the collapse of the subsite-2 region. In contrast, the state of both subpockets is coupled in the $\mathrm{Y} 220 \mathrm{H}$ mutant, where displacement of His220 favors the coordinated collapse of both subsites (Figure $3 \mathrm{~B}$ and Supporting Information Figure S5).

Carbazole-Based Y220C Binders Also Bind to the Y220S and Y220N Mutants. Given the similarity of the mutation-induced surface crevice in the structures of the Y220C and Y220S mutants, we speculated that the molecules we had previously designed for rescuing the function of the Y220C mutant might also bind to the Y220S mutant and stabilize it. We therefore tested a selection of our carbazolebased lead structures by DSF thermal shift assays and determined the binding constant, $K_{\mathrm{d}}$, of a few selected compounds by isothermal calorimetry (ITC; Table 3). All Y220C binders tested also stabilized the Y220S mutant, albeit to a different extent. Generally, compounds with a larger subsite- 2 moiety had a much smaller stabilizing effect on the 
Table 4. Differential Stabilization of Y220X Mutants<smiles>[R2]c1ccc2c3cc(CN([R3])C)ccc3n([R1])c2c1</smiles>

\begin{tabular}{|c|c|c|c|c|c|c|c|c|}
\hline \multirow[b]{2}{*}{ Cpd. } & \multirow[b]{2}{*}{$\mathrm{R} 1$} & \multirow[b]{2}{*}{$\mathrm{R} 2$} & \multirow[b]{2}{*}{$\mathrm{R} 3$} & \multicolumn{5}{|c|}{$\Delta T_{\mathrm{m}}\left({ }^{\circ} \mathrm{C}\right)^{\mathrm{a}}$} \\
\hline & & & & WT & Y220C & Y220S & $\mathrm{Y} 220 \mathrm{~N}$ & $\mathrm{Y} 220 \mathrm{H}$ \\
\hline PK9255 & $\mathrm{CH}_{2} \mathrm{CF}_{3}$ & $\mathrm{H}$ & $\mathrm{H}$ & $0.0 \pm 0.1$ & $1.7 \pm 0.1$ & $3.2 \pm 0.0$ & $1.4 \pm 0.1$ & $0.2 \pm 0.1$ \\
\hline PK9285 & $\mathrm{CH}_{2} \mathrm{CH}_{3}$ & $\mathrm{Br}$ & $\mathrm{CH}_{3}$ & $-0.2 \pm 0.1$ & $2.0 \pm 0.0$ & $2.1 \pm 0.1$ & $1.4 \pm 0.1$ & $0.2 \pm 0.0$ \\
\hline PK9321 & $\mathrm{CH}_{2} \mathrm{CH}_{3}$ & & $\mathrm{H}$ & $0.2 \pm 0.1$ & $3.1 \pm 0.1$ & $2.1 \pm 0.1$ & $1.4 \pm 0.1$ & $0.7 \pm 0.1$ \\
\hline PK9323 & $\mathrm{CH}_{2} \mathrm{CH}_{3}$ & & $\mathrm{H}$ & $-0.4 \pm 0.2$ & $3.1 \pm 0.1$ & $3.7 \pm 0.3$ & $0.7 \pm 0.1$ & $-0.3 \pm 0.1$ \\
\hline
\end{tabular}

${ }^{a}$ Measured at a compound concentration of $250 \mu \mathrm{M}$. Mean values of triplicate measurements \pm SEM are shown.

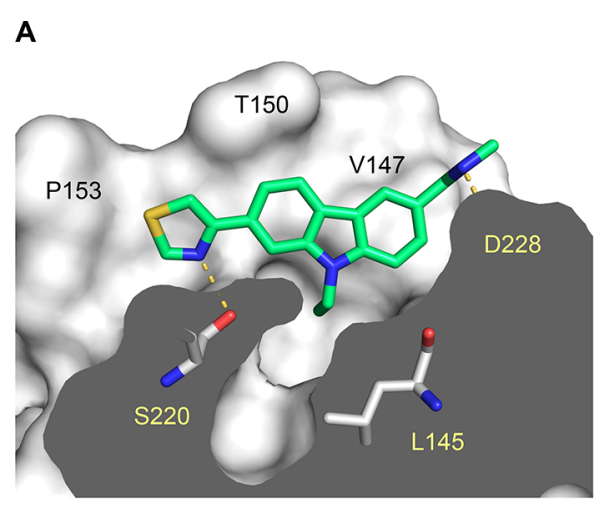

B

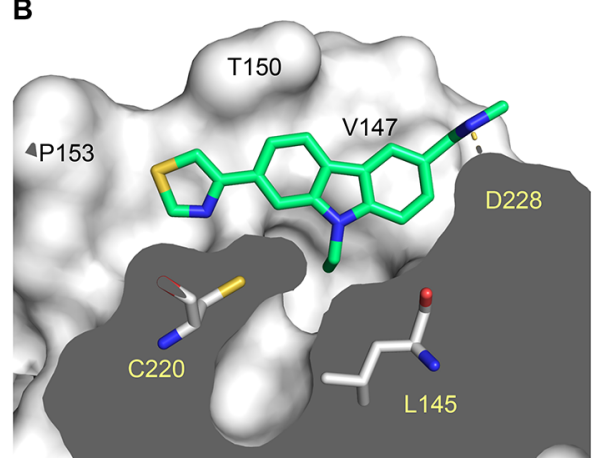

C

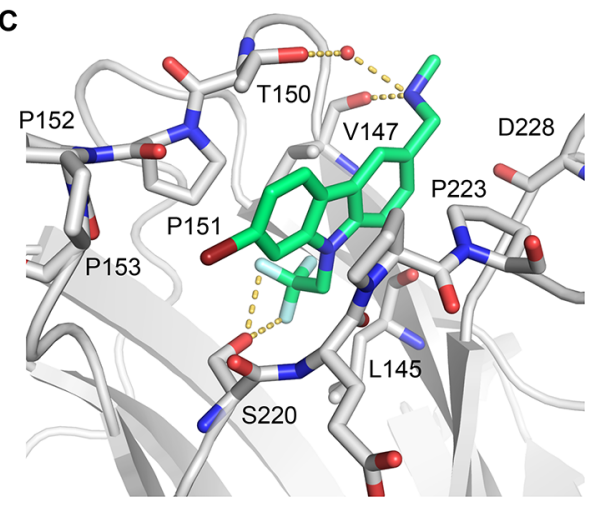

D

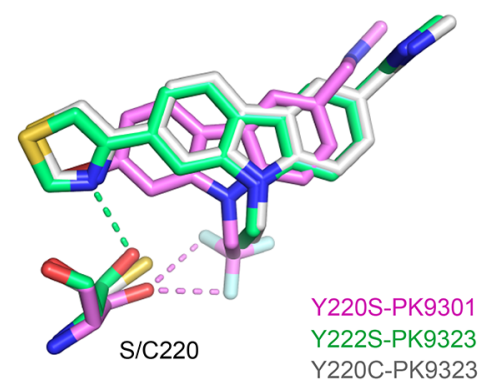

Figure 4. Structures of the p53-Y220S mutant in complex with PK9301 and PK9323. (A) Molecular surface representation of a cross-section of the mutation-induced surface crevice in the Y220S mutant with bound PK9323, showing that the thiazole moiety of the ligand forms a hydrogen bond with Ser220. (B) Structure of the Y220C-PK9323 complex; same view as for the Y220S-PK9323 complex in A. (C) Structure of the Y220SPK9301 complex. Key residues in the binding pocket are shown as stick models. A structural water molecule interacting with the aminomethyl substituent is shown as a red sphere. Ligand-mediated hydrogen bonds are shown as orange dashed lines. (D) Superposition of the binding modes of PK9323 in Y220S and Y220C as well as PK9301 in Y220S. The ligands and the mutated side chain are shown as stick models. Polar interactions with Ser220 are shown as dashed lines in the same color as the corresponding structure.

Y220S than on the Y220C mutant at a given concentration, with a notable exception being PK9322 and PK9323, which stabilized both mutants equally well. Both compounds contain a thiazole moiety that can potentially form a hydrogen bond with Ser220. In contrast, compounds with a trifluoroethyl anchor and lacking extensive subsite-2 extensions had a more stabilizing effect on Y220S than on Y220C. The highest thermostabilization among all compounds tested was observed for PK9301, which increased the $T_{\mathrm{m}}$ of the Y220S mutant by more than $5{ }^{\circ} \mathrm{C}$, higher than any stability increase observed for the Y220C mutant to date. PK9301 bound to Y220S with a $K_{d}$ of $4 \mu \mathrm{M}$ (Supporting Information Figure S6), a slightly higher affinity than determined previously for the Y220C mutant $\left(K_{d}\right.$ $=6 \mu \mathrm{M})$. The preference of Y220S for a trifluorylated ethyl anchor was even more pronounced in the absence of a subsite2 targeting moiety. PK9255 bound about 2 times more tightly to the Y220S mutant ( $K_{\mathrm{d}}=16 \mu \mathrm{M}$ vs $K_{\mathrm{d}}=28 \mu \mathrm{M}$ for Y220C). When comparing the compound-induced thermal shifts for the 
two mutants, one has to take into consideration that the Y220S mutation has a higher destabilizing effect than the Y220C mutation $\left(\Delta T_{\mathrm{m}}\right.$ of 12 vs $\left.8{ }^{\circ} \mathrm{C}\right)$. The potential stability gains from optimally targeting the Y220S (and also Y220N) pocket are therefore expected to be higher than from targeting the Y220C pocket.

We also tested a few representative carbazoles against the $\mathrm{Y} 220 \mathrm{~N}$ and $\mathrm{Y} 220 \mathrm{H}$ mutants (Table 4). Intriguingly, PK9255 also stabilized the $\mathrm{Y} 220 \mathrm{~N}$ mutant by $1.4^{\circ} \mathrm{C}$ and bound with a $K_{\mathrm{d}}$ of $40 \mu \mathrm{M}$ as measured by ITC (Supporting Information Figure S7). Larger compounds with a subsite-2 extension had no additional stabilizing effects and were in one case actually less effective in stabilizing Y220N than PK9255, clearly indicating significant differences in the binding mode and/or the architecture of the Y220N pocket. PK9255 had no significant stabilizing effect on the $\mathrm{Y} 220 \mathrm{H}$ mutant, consistent with the crystal structure of the mutant showing that the histidine side chain effectively blocks the center of the binding pocket. These data establish that the mutation-induced pocket in the Y220N mutant is also druggable but requires a different design strategy or an alternative scaffold to optimally target it.

Binding Modes of Carbazole-Based Y220S Mutant Stabilizers. To provide a rationale for the observed binding affinities, we determined crystal structures of the Y220S mutant in complex with the best stabilizers, PK9301 and PK9323, as well as the structure of the Y220C mutant with PK9323. The resolution of the structures ranged from 1.4 to $1.8 \AA$, and there was clear electron density for the bound ligand in each case. The overall binding mode of PK9323 in the Y220S mutant resembles closely that observed for other carbazoles bound to the Y220C mutant (Figure 4A,B). The carbazole ring system is flanked on one side by Val147, Thr150, and Pro151 and on the other side by Pro222, Pro223, and Thr230. The secondary amine forms a hydrogen bond with the backbone oxygen of Asp228, and the ethyl anchor forms hydrophobic interactions in the subsite- 3 region at the bottom of the binding pocket. The subsite- 2 thiazole moiety shows good shape complementarity with this subpocket, with the sulfur atom facing Pro153. Importantly, the thiazole nitrogen forms a hydrogen bond with the Ser220 hydroxyl (2.9 $\AA$ distance), which explains the preference of the Y220S mutant for thiazole-substituted carbazoles over other subsite-2 targeting moieties (Table 3). Compared with the structure of the Y220C-PK9323 complex, the overall scaffold is shifted slightly toward subsite 2 in the Y220S mutant, and the thiazole ring shows a stronger deviation from coplanarity with the carbazole ring system to accommodate the binding pocket (average dihedral angle of $14^{\circ}$ vs $5^{\circ}$ ).

Relative to its orientation in most Y220C complexes, the PK9301 carbazole scaffold is shifted slightly toward subsite 2, with the bromine substituent reaching into this subsite, where it forms extensive hydrophobic interactions (Figure 4C,D). In the subsite- 3 region at the bottom of the binding pocket, two fluorine atoms of the trifluoroethyl anchor form a weak hydrogen bond with the Ser220 hydroxyl group each (distance of 3.0 and $3.1 \AA$, respectively), and one strongly polarized proton next to the trifluoromethyl group interacts with the hydroxyl oxygen atom via weak hydrogen bonding ( $\mathrm{C} \cdots \mathrm{O}$ distance $=3.3 \AA$ ). These interactions rationalize why a trifluoroethyl anchor is strongly favored over an ethyl anchor (cf. Table 3). The third fluorine atom points toward the backbone carbonyls of Leu145 and Trp146, as seen for the Y220C mutant, where it forms orthogonal multipolar interactions. The $\mathrm{F} \cdots \mathrm{O}=\mathrm{C}$ distance is 3.9 and $4.2 \AA$, respectively, which is slightly larger than the typical interaction distance $(3.0-3.7 \AA),{ }^{35}$ indicating that the trifluoroethyl group prefers to interact with the Ser220 side chain. Instead of directly interacting with the Asp228 backbone, as seen for PK9323, the secondary methylamine group forms a hydrogen bond with the backbone oxygen of Val147 and a number of water-mediated contacts with the protein, for example, with the Thr150 side chain at the entrance of the pocket.

Taken together, the analysis of the ligand binding modes in the Y220S and Y220C mutant and the SAR (Table 3) provide a framework for the design of binders with dual Y220C/Y220S specificity.

Reduced Dynamics of the Y220C and Y220S Mutant Proteins upon Ligand Binding. We performed additional $\mathrm{MD}$ simulations on the Y220C/S-ligand structures described above (Y220S-PK9301, Y220S-PK9323, and Y220CPK9323) to gain insights into the effect of ligand binding on the dynamics of the mutant proteins. After aligning the protein backbone of all trajectory frames to the initial conformation, the all-atom RMSD of the ligand with respect to its initial conformation was calculated. These values fluctuated around an average of $2.1 \AA$ for the two PK9323 complexes and $1.8 \AA$ for the Y220S-PK9301 complex, with a standard deviation of $0.5 \AA$ in all three cases. The small fluctuations around the initial structure indicate that the protein-ligand complexes were very stable during the time scale of the simulations. Ligand binding stabilized the protein in all three simulations, resulting in drastically reduced average RMSFs compared with the unbound mutant structure (Table S1). For the Y220CPK9323 complex, the overall RMSF was actually lower than that of the wild-type DBD. For the Y220S-ligand complexes studied, PK9323 and PK9301, reduction of the average RMSF correlated with the affinity and effect on thermostability of the compound, i.e., the more potent binder and stabilizer PK9301 induced a stronger decrease of the average RMSF than PK9323 (cf. Tables 3 and S1). Analysis of the RMSF for individual residues also provided interesting information (Supporting Information Figure S8). The elevated RMSFs for residues on both sides of the mutation-induced binding pocket in the MD simulations of the native Y220C and Y220S mutant, i.e., residues $147-153$ and around residue 220 , went back to wildtype levels upon ligand binding, indicating stabilization of the local structure of the pocket region. This local stabilization was also reflected in the distances of specific pocket parameters describing the state of the central cavity (d1) and subsite 2 (d2), i.e., the distances between the $\mathrm{C} \delta$ atoms of Pro151 and Pro223 (d1) and between the $\mathrm{C} \alpha$ atom of Pro153 and the $\mathrm{C} \gamma$ atom of Pro222 (d2; see Figure 3). In the MD simulations of the native mutants, there was a bimodal distribution of both pocket parameters, corresponding to open and collapsed states of the pocket. In contrast, in both the Y220C and Y220S ligand complexes, there was a reversal to a unimodal distribution, as seen for the wild type, and the distances stayed close to the values in the starting structure throughout the simulation (Figures S3 and S4). Comparison of the subsite-2 parameter, $\mathrm{d} 2$, in the two Y220S-ligand complex simulations also shows that there is a slight narrowing of subsite 2 with PK9301, which has a smaller subsite- 2 targeting moiety than PK9323 (bromine vs thiazole). Especially in the Y220S-ligand complexes, a number of long-range effects were also observed, resulting in reduced structural fluctuations in the distant L2 and L3 loops in the ligand-bound mutant (Figure S8). 
Overall, the MD simulations support the notion that our molecules act as a molecular glue that stabilizes both the local and global structure, reducing conformational sampling and increasing the thermostability of the Y220X mutant proteins.

\section{CONCLUSION AND OUTLOOK}

We have shown that the four most common oncogenic Y220X mutations drastically impair the thermostability of the p53 DBD. Crystal structures and MD simulations further revealed that three of them result in the formation of an extended surface crevice with unique properties. Importantly, our data establish that both the Y220S and Y220N mutants, in addition to the $\mathrm{Y} 220 \mathrm{C}$ mutant, are druggable targets for restoring the function of those mutants in tumors with small-molecule stabilizers. The structural and biophysical data presented here provide a framework for the development of both specific and dual Y220S/Y220C stabilizers, whereas the Y220N mutant most likely requires a different design strategy for achieving the required potency. In addition, MD simulations provided complementary structural and dynamical information that can inform the rational design and optimization of Y220X ligands. Systematic structural studies on other p53 cancer mutants, combined with virtual and fragment screening approaches, are likely to unearth more oncogenic variants with druggable pockets. These studies should further expand the druggable p53 mutome for cancer therapy and aid the development of new personalized cancer drugs.

Shortly before submission of this manuscript, a docking study with our initial Y220C stabilizer PK083 was published, suggesting that it may preferentially bind to the Y220S mutant, although no experimental verification was provided. ${ }^{36}$

\section{MATERIALS AND METHODS}

Compound Synthesis. Synthesis routes of chemical compounds, except PK9301, have been described elsewhere. ${ }^{17}$ 1-(7-Bromo-9(2,2,2-trifluoroethyl)-9H-carbazol-3-yl)-N-methylmethanamine (PK9301). To a solution of 7-bromo-9H-carbazole-3-carbaldehyde $(200 \mathrm{mg}, 0.72 \mathrm{mmol})$, in anhydrous DMF $(3 \mathrm{~mL})$, was added cesium carbonate $(475 \mathrm{mg}, 1.45 \mathrm{mmol})$ and 2,2,2-trifluoroethyl- $p$-toluenesulfonate $(356 \mathrm{mg}, 1.45 \mathrm{mmol})$. The reaction mixture was irradiated in the microwave at $150{ }^{\circ} \mathrm{C}$ for $30 \mathrm{~min}$. After cooling, the crude product was purified by chromatography on silica gel using EtOAc/hexane 1/4 to $1 / 1$ over $20 \mathrm{~min}$. 7-Bromo-9-(2,2,2-trifluoroethyl)-9H-carbazole-3carbaldehyde was isolated as a white solid, yield $52 \%(134 \mathrm{mg}, 0.37$ mmol). ${ }^{1} \mathrm{H}$ NMR (500 MHz, DMSO- $\left.d_{6}\right): \delta 10.06(\mathrm{~s}, 1 \mathrm{H}, \mathrm{CHO}), 8.78$ $(\mathrm{s}, 1 \mathrm{H}$, ar $\mathrm{CH}), 8.25(\mathrm{~d}, J=8.5 \mathrm{~Hz}, 1 \mathrm{H}$, ar CH$), 8.14(\mathrm{~s}, 1 \mathrm{H}$, ar $\mathrm{CH})$, $8.05(\mathrm{~d}, J=8.5 \mathrm{~Hz}, 1 \mathrm{H}$, ar CH), $7.91(\mathrm{~d}, J=8.5 \mathrm{~Hz}, 1 \mathrm{H}$, ar $\mathrm{CH}), 7.49$ $(\mathrm{d}, J=8.5 \mathrm{~Hz}, 1 \mathrm{H}$, ar $\mathrm{CH}), 5.55\left(\mathrm{q},{ }^{3} J_{\mathrm{FH}}=9.2 \mathrm{~Hz}, 2 \mathrm{H}, \mathrm{CH}_{2}\right) \mathrm{ppm}$. ${ }^{13} \mathrm{C}$ NMR $\left(126 \mathrm{MHz}\right.$, DMSO- $\left.d_{6}\right): \delta 192.3,144.3,142.3,130.2,127.9$, $125.3\left(\mathrm{q},{ }^{1} J_{\mathrm{FC}}=281.7 \mathrm{~Hz}\right), 124.5,124.2,123.0,122.7,122.1,120.4$, $113.9,11.2,44.1\left(\mathrm{q},{ }^{2} J_{\mathrm{FC}}=33.0 \mathrm{~Hz}\right)$ ppm. MS-EI $(\mathrm{m} / \mathrm{z})$ found: 355 $[\mathrm{M}]^{+}$. Calcd.: 355 .

To a solution of the latter compound ( $85 \mathrm{mg}, 0.24 \mathrm{mmol})$, used as such, in anhydrous EtOH/DCM $(2 \mathrm{~mL})$ was added methylamine hydrochloride (32 mg, $0.48 \mathrm{mmol}$ ), triethylamine (49 $\mu \mathrm{L}, 0.35$ $\mathrm{mmol}$ ), and titanium(IV) isopropoxide (141 $\mu \mathrm{L}, 0.48 \mathrm{mmol})$. The resulting solution was stirred at RT for $18 \mathrm{~h}$ before the addition of sodium borohydride $(18 \mathrm{mg}, 0.48 \mathrm{mmol})$. The solution was stirred at RT for $8 \mathrm{~h}$ before pouring into $2 \mathrm{M}$ aqueous ammonia solution (10 $\mathrm{mL}$ ). The suspension was filtered through Celite, and to the filtrate was added $\mathrm{H}_{2} \mathrm{O}$. Crude product was extracted with DCM, dried over anhydrous $\mathrm{K}_{2} \mathrm{CO}_{3}$. The suspension was filtered, and the filtrate was concentrated in vacuo to yield crude product that was purified by chromatography on silica gel using 9:1 $\mathrm{DCM} / \mathrm{MeOH}$ as an eluent to yield the product as a colorless solid, yield: $36 \%(32 \mathrm{mg}, 0.08 \mathrm{mmol})$. ${ }^{1} \mathrm{H}$ NMR (500 MHz, DMSO- $\left.d_{6}\right): \delta 8.32(\mathrm{~s}, 1 \mathrm{H}$, ar CH), $8.08(\mathrm{~s}, 1 \mathrm{H}$, ar $\mathrm{CH}), 8.05(\mathrm{~d}, J=8.5 \mathrm{~Hz}, 1 \mathrm{H}$, ar $\mathrm{CH}), 7.80(\mathrm{~d}, J=8.5 \mathrm{~Hz}, 1 \mathrm{H}$, ar $\mathrm{CH}), 7.69(\mathrm{~d}, J=8.5 \mathrm{~Hz}, 1 \mathrm{H}$, ar $\mathrm{CH}), 7.44(\mathrm{~d}, J=8.5 \mathrm{~Hz}, 1 \mathrm{H}$, ar $\mathrm{CH}), 5.49\left(\mathrm{q},{ }^{3} J_{\mathrm{FH}}=9.0 \mathrm{~Hz}, 2 \mathrm{H}, \mathrm{CH}_{2}\right), 4.23\left(\mathrm{~s}, 2 \mathrm{H}, \mathrm{CH}_{2}\right), 2.53(\mathrm{~s}$, $\left.3 \mathrm{H}, \mathrm{CH}_{3}\right)$ ppm. ${ }^{13} \mathrm{C}$ NMR $\left(126 \mathrm{MHz}, \mathrm{DMSO}-d_{6}\right): \delta 141.9,140.9$, $128.9,124.5,123.7,123.4\left(\mathrm{q},{ }^{1} J_{\mathrm{FC}}=285.3 \mathrm{~Hz}\right), 122.8,122.4,122.3$, $121.8,119.8,113.6,110.8,51.9,43.9\left(\mathrm{q},{ }^{2} J_{\mathrm{FC}}=33.2 \mathrm{~Hz}\right), 32.2 \mathrm{ppm}$. HRMS-ESI $(\mathrm{m} / z)$ found: $339.9470[\mathrm{M}]+$. Calcd.: 339.9943 for $\left[\mathrm{C}_{15} \mathrm{H}_{10} \mathrm{BrF}_{3} \mathrm{~N}\right]^{+}$(loss of NHMe). LC-MS purity $=97 \%(\mathrm{UV})$, ret. time $=12.55 \mathrm{~min}$.

Differential Scanning Fluorimetry. Melting temperatures of the p53 mutants were determined by differential scanning fluorimetry (DSF) using the dye SYPRO Orange (Invitrogen), which quantitatively binds to hydrophobic protein patches that become exposed upon thermal unfolding. Real-time melt analyses were performed using either an Agilent MX3005P (heating rate of $270 \mathrm{~K} / \mathrm{h}$ excitation/emission filters $=492 / 610 \mathrm{~nm}$; Tables 2 and 4) or a Corbett Rotor-Gene 6000 real-time qPCR thermocycler (heating rate of $180 \mathrm{~K} / \mathrm{h}$, excitation/emission filters $=460 / 510 \mathrm{~nm}$; Table 3). $T_{\mathrm{m}}$ measurements were performed with $8 \mu \mathrm{M}$ p53 protein and 5-10 $\times$ SYPRO Orange (Life Technologies) in a $25 \mathrm{mM} \mathrm{KPi} \mathrm{(pH} \mathrm{7.2),} 150$ $\mathrm{mM} \mathrm{NaCl}$, and $1 \mathrm{mM}$ TCEP assay buffer. For measurements of compound-induced $T_{\mathrm{m}}$ shifts $\left(\Delta T_{\mathrm{m}}\right)$, the assay buffer additionally contained $5 \%$ DMSO $(\mathrm{v} / \mathrm{v})$, with either $250 \mu \mathrm{M}$ ligand or no ligand (control). $\Delta T_{\mathrm{m}}$ values were calculated as $\Delta T_{\mathrm{m}}=T_{\mathrm{m}}$ (protein + compound) $-T_{\mathrm{m}}$ (protein). Native melting curves were measured in quadruplicate and compound-induced thermal shifts in triplicate or higher. Mean values \pm SEM are given.

Isothermal Titration Calorimetry. Isothermal titration calorimetry (ITC) experiments for the Y220C and Y220S mutants were performed using a MicroCal (Amherst) iTC200 calorimeter as described. ${ }^{14}$ Briefly, the cell unit contained $30-50 \mu \mathrm{M}$ protein in a 25 $\mathrm{mM} \mathrm{KPi} \mathrm{(pH} \mathrm{7.2),} 150 \mathrm{mM} \mathrm{NaCl}, 1 \mathrm{mM}$ TCEP, and 5\% (v/v) DMSO assay buffer. The syringe contained $0.5-2 \mathrm{mM}$ compound in the same buffer, using injection steps of $2 \mu \mathrm{L}$ at a rate of $0.5 \mu \mathrm{L} / \mathrm{s}$ (initial injection: $0.5 \mu \mathrm{L}$ ) and $120 \mathrm{~s}$ spacing. For the poorly soluble PK9223, a reverse titration was performed. Data analysis was performed using the MicroCal Origin software. ITC measurements for the Y220N mutant were carried out with the same buffers as above but using a Nano ITC microcalorimeter (TA Instruments) and injection steps of $8 \mu \mathrm{L}$, at a rate of $0.5 \mu \mathrm{L} / \mathrm{s}$, and $200 \mathrm{~s}$ spacing. Data were processed using the NanoAnalyze software (Version 3.5.0) supplied with the instrument. All measurements were performed at 20 ${ }^{\circ} \mathrm{C}$.

Protein Expression and Purification. Protein expression and purification were performed following published protocols. ${ }^{11}$ Briefly, we used a pET24a-based expression vector encoding a fusion protein with an N-terminal 6xHis tag, followed by the lipoyl domain of the dihydrolipoamide acetyltransferase from Bacillus stearothermophilus, a TEV protease cleavage site, and the mutant p53 DBD (residues 94312 ) of interest. Point mutations in the p53 DBD were introduced using the QuickChange site-directed mutagenesis kit (Agilent). All mutations were introduced into a stabilized quadruple mutant variant of the human DBD (M133L/V203A/N239Y/N268D) that we used successfully for studying the effects of destabilizing p53 mutations in the past. ${ }^{10,37}$ The recombinant proteins were expressed in E. coli C41. Cells harboring the expression vector were grown in $2 \mathrm{TY}$ medium at $37{ }^{\circ} \mathrm{C}$ up to an $\mathrm{OD}_{600}=0.6-0.8$. At this point, the temperature was lowered to $20{ }^{\circ} \mathrm{C}$, and protein expression was induced by adding IPTG $(0.5 \mathrm{mM})$. The cells were further supplemented with $0.1 \mathrm{mM}$ zinc chloride. Cells were grown overnight and then broken by either sonication or French press. The p53 mutants were purified using a nickel column, followed by TEV protease cleavage overnight and a second purification step on a heparin column. After an additional gel filtration chromatography step, the mutants were concentrated to 6 $\mathrm{mg} \mathrm{mL} \mathrm{m}^{-1}$, flash frozen in liquid nitrogen, and stored at $-80{ }^{\circ} \mathrm{C}$.

Protein Crystallization and Structure Determination. Crystals of the Y220C, Y220S, and Y220H mutant were grown at $20{ }^{\circ} \mathrm{C}$ using the sitting drop vapor diffusion technique by mixing equal amounts of protein solution $\left(6 \mathrm{mg} \mathrm{mL}^{-1}\right.$ mutant protein in $25 \mathrm{mM}$ phosphate buffer, $\mathrm{pH} 7.2,150 \mathrm{mM} \mathrm{NaCl}$, and $5 \mathrm{mM} \mathrm{DTT}$ ) and 
Table 5. X-ray Data Collection and Refinement Statistics

\begin{tabular}{|c|c|c|c|c|c|c|}
\hline structure & Y220C & Y220C-9323 & $\mathrm{Y} 220 \mathrm{H}$ & $\mathrm{Y} 220 \mathrm{~S}$ & Y220S-9301 & Y220S-9323 \\
\hline \multicolumn{7}{|l|}{ data collection } \\
\hline space group & $P 2_{1} 2_{1} 2_{1}$ & $P 2_{1} 2_{1} 2_{1}$ & $P 2_{1} 2_{1} 2_{1}$ & $P 2_{1} 2_{1} 2_{1}$ & $P 2_{1} 2_{1} 2_{1}$ & $P 2_{1} 2_{1} 2_{1}$ \\
\hline$a(\AA)$ & 65.18 & 64.88 & 64.76 & 65.06 & 64.98 & 65.22 \\
\hline$b(\AA)$ & 71.15 & 71.14 & 70.77 & 71.22 & 71.30 & 71.19 \\
\hline$c(\AA)$ & 105.04 & 104.74 & 104.88 & 105.40 & 105.72 & 105.16 \\
\hline molecules/AU & 2 & 2 & 2 & 2 & 2 & 2 \\
\hline resolution $(\AA)^{a}$ & $\begin{array}{l}29.5-1.24 \\
\quad(1.31-1.24)\end{array}$ & $\begin{array}{l}47.9-1.53 \\
\quad(1.56-1.53)\end{array}$ & $\begin{array}{l}47.8-1.44 \\
\quad(1.47-1.44)\end{array}$ & $\begin{array}{l}29.6-1.50 \\
\quad(1.58-1.50)\end{array}$ & $\begin{array}{l}29.6-1.40 \\
\quad(1.48-1.40)\end{array}$ & $\begin{array}{l}48.1-1.80 \\
\quad(1.84-1.80)\end{array}$ \\
\hline unique reflections & 135,992 & 72,947 & 86,307 & 78,532 & 96,281 & 45,643 \\
\hline completeness $(\%)^{a}$ & $98.0(96.2)$ & $99.0(97.7)$ & $98.5(97.7)$ & $99.4(99.4)$ & $99.3(99.4)$ & $99.1(99.9)$ \\
\hline multiplicity ${ }^{a}$ & $5.5(5.5)$ & $4.1(3.9)$ & $5.5(5.6)$ & $4.7(4.6)$ & $4.7(4.7)$ & $4.3(4.4)$ \\
\hline$R_{\text {merge }}(\%)^{a}$ & $5.3(58.2)$ & $5.3(63.6)$ & $8.6(63.5)$ & $6.0(52.9)$ & $5.3(48.4)$ & $8.9(54.1)$ \\
\hline $\operatorname{CC}(1 / 2)^{a}$ & $0.999(0.887)$ & $0.999(0.798)$ & $0.995(0.888)$ & $0.999(0.875)$ & $0.999(0.895)$ & $0.996(0.873)$ \\
\hline mean $I / \sigma(I)^{a}$ & $15.6(3.1)$ & $14.1(2.5)$ & $9.3(2.4)$ & $14.5(2.9)$ & $13.1(3.0)$ & $8.9(2.5)$ \\
\hline \multicolumn{7}{|l|}{ refinement } \\
\hline$R_{\text {work }}(\%)^{b}$ & 15.1 & 14.3 & 15.2 & 14.7 & 15.1 & 19.0 \\
\hline$R_{\text {free }}(\%)^{b}$ & 17.2 & 17.3 & 17.8 & 17.7 & 17.6 & 22.4 \\
\hline \multicolumn{7}{|l|}{ no. of atoms } \\
\hline protein $^{c}$ & 3171 & 3100 & 3131 & 3082 & 3117 & 3064 \\
\hline zinc & 2 & 2 & 2 & 2 & 2 & 2 \\
\hline water & 513 & 474 & 516 & 474 & 445 & 392 \\
\hline ligands & 14 & 71 & 31 & 18 & 62 & 52 \\
\hline RMSD bonds $(\AA)$ & 0.005 & 0.006 & 0.006 & 0.005 & 0.005 & 0.006 \\
\hline $\begin{array}{l}\text { RMSD angles } \\
\text { (deg) }\end{array}$ & 0.8 & 0.8 & 0.8 & 0.8 & 0.8 & 0.8 \\
\hline mean $B\left(\AA^{2}\right)$ & 18.5 & 21.0 & 18.8 & 22.6 & 21.5 & 22.6 \\
\hline PDB entry & $6 \mathrm{SHZ}$ & 6SI0 & 6SI1 & $6 \mathrm{SI} 2$ & $6 \mathrm{SI} 3$ & $6 \mathrm{SI} 4$ \\
\hline
\end{tabular}

${ }^{a}$ Values in parentheses are for the highest resolution shell. ${ }^{b} R_{\text {work }}$ and $R_{\text {free }}=\sum\left\|F_{\text {obs }}|-| F_{\text {calc }}\right\| / \sum\left|F_{\text {obs }}\right|$, where $R_{\text {free }}$ was calculated with $5 \%$ of the reflections chosen at random and not used in the refinement. ${ }^{c}$ Number includes alternative conformations.

reservoir buffer $(19 \%(\mathrm{w} / \mathrm{v})$ polyethylene glycol 4000, $100 \mathrm{mM}$ HEPES, pH 7.2, and 5 mM DTT). Rod shaped crystals grew within a few days. Crystals of the Y220S-PK9323 complex were grown under the same conditions but with the crystallization buffer supplemented with $2 \mathrm{mM}$ PK9323. All crystals were cryoprotected with mother liquor supplemented with $20 \%$ glycerol and flash frozen in liquid nitrogen. For additional soaking experiments, crystals of the Y220S mutant were soaked for $60 \mathrm{~min}$ in a saturated solution of PK9301 in cryoprotection buffer prior to flash freezing, and crystals of the Y220C mutant were soaked for $3.5 \mathrm{~h}$ with a saturated solution of PK9323 in the same cryoprotection buffer as above prior to flash freezing. X-ray data sets were collected at $100 \mathrm{~K}$ at beamline I03 of the Diamond Light Source, Oxford, UK, and beamline X06SA of the Swiss Light Source, Villigen, Switzerland. The diffraction data were integrated with the program $\mathrm{XDS}^{38}$ and scaled with either SCALA ${ }^{39}$ or AIMLESS, ${ }^{40}$ which are both implemented in the CCP4 package. ${ }^{41}$ The structures were solved by difference Fourier analysis in PHENIX $^{42}$ using PDB entry 2J1X as a starting model with initial rigid body refinement. Structure refinement was performed using iterative cycles of manual model building in $\mathrm{COOT}^{43}$ and refinement in PHENIX. Dictionary files for the PK9301 and PK9323 ligands were generated using the Grade Web Server (http://grade.globalphasing. org). In the structure of the Y220S complex with the brominated ligand PK9301, there was significant negative difference electron density at the bromine after refinement, as observed previously for a similar compound with the Y220C mutant, ${ }^{17}$ suggesting a partial, radiation-induced loss of the bromine atom. Data collection and refinement statistics are listed in Table 5. Structural figures were prepared using PyMOL (www.pymol.org).

Molecular Dynamics Simulations. Molecular dynamics (MD) simulations were set up for the DBD of stabilized pseudo-wild-type p53 and the four Y220X mutants of this scaffold. Starting models were PDB entries 1 UOL and the mutant crystal structures determined in this study (chain A). For the Y220N mutant, a model using SWISS-
MODEL $^{33}$ with the Y220C mutant structure (PDB ID: 2J1X) as a template was used. Ligands (e.g., buffer molecules, glycerol from the crystallization conditions) were removed from the calculations. The structures of the mutants were solvated in truncated octahedron simulation boxes with walls at least $1.2 \mathrm{~nm}$ away from the protein. The TIP $3 \mathrm{P}^{44}$ model was used for the explicit simulation of water molecules. The system was neutralized and taken to physiological ion concentration $(0.15 \mathrm{M})$ by changing some water molecules into sodium and chlorine ions. Simulations were carried out with the CHARMM $36 \mathrm{~m}$ force field ${ }^{45}$ and the program GROMACS.2018. ${ }^{46}$ The zinc ion and the coordinating cysteine/histidine residues were modeled according to Budiman et al. and Godwin et al. ${ }^{47,48}$ This resulted in systems comprising between 35570 and 42173 atoms. The temperature of the system was kept constant at $300 \mathrm{~K}$ using a Nosé-Hoover thermostat ${ }^{49,50}$ with $\tau_{\mathrm{t}}=1 \mathrm{ps}$, and the pressure was kept constant at 1 bar with the Parrinello-Rahman algorithm ${ }^{51}$ with $\tau_{\mathrm{p}}=1 \mathrm{ps}$. Direct nonbonded interactions were cut off at $1.2 \mathrm{~nm}$ with a switch function on Van-der-Waals interactions starting at $1.0 \mathrm{~nm}$. Long-range electrostatic interactions were computed using sPME. ${ }^{52}$ The covalent bonds with hydrogen atoms were constrained with the LINCS algorithm, ${ }^{53}$ and the integration time step was set to $2 \mathrm{fs}$. The systems were minimized for a max 50000 steps, then equilibrated in the NVT ensemble for $1 \mathrm{~ns}$ with positional restraints on the positions of the heavy atoms of the protein. Then, they were further equilibrated for $1 \mathrm{~ns}$ in the NPT ensemble with no restraints. Four production runs were started for each mutant. Each run was $200 \mathrm{~ns}$ long. The resulting trajectories were analyzed using $\mathrm{VMD}^{54}$ and WORDOM. ${ }^{55}$

PK9301 and PK9323 ligands were modeled using the CHARMM general force field ( $\mathrm{CGenFF}^{56} 4.0$, program version 2.2.0, https:// cgenff.umaryland.edu) based on their similarity to previously parametrized compounds. The very small deviation observed along the MD simulations (maximal average RMSD of $2.1 \AA$ over all atoms including hydrogens) of the ligands from their position in the 
crystallographic structure (after addition and minimization of the hydrogens) confirmed that the parametrization was appropriate.

\section{ASSOCIATED CONTENT}

\section{(s) Supporting Information}

The Supporting Information is available free of charge at https://pubs.acs.org/doi/10.1021/acschembio.9b00748.

Model of the mutation-induced cavity in the p53-Y220N mutant; RMSFs of $\mathrm{C}_{\alpha}$ atoms in MD simulations of $\mathrm{p} 53$ Y220X mutant DBDs and correlation between average RMSFs and protein thermostability; selected pocket parameters as a function of time over all MD simulations of Y220X mutant DBDs; correlation between subsite 2 and the central cavity in the MD simulations of the Y220S, Y220C, and $\mathrm{Y} 220 \mathrm{H}$ mutant; ITC curve for binding of PK9301 to mutant Y220S and binding of PK9255 to mutant Y220N (PDF)

\section{Accession Codes}

Coordinates and structure factors of the p53-Y220X mutant structures have been deposited in the Protein Data Bank (PDB). Accession codes: 6SHZ, 6SI0, 6SI1, 6SI2, 6SI3, and 6 SI4.

\section{AUTHOR INFORMATION}

\section{Corresponding Author}

Andreas C. Joerger - Institute of Pharmaceutical Chemistry, Johann Wolfgang Goethe University, 60438 Frankfurt am Main, Germany; Buchmann Institute for Molecular Life Sciences and Structural Genomics Consortium (SGC), 60438 Frankfurt am Main, Germany; 이이.org/0000-0002-1232-0138; Email: joerger@pharmchem.uni-frankfurt.de

\section{Authors}

Matthias R. Bauer - MRC Laboratory of Molecular Biology, Cambridge CB2 OQH, United Kingdom; (1) orcid.org/00000003-4015-6483

Andreas Krämer - Institute of Pharmaceutical Chemistry, Johann Wolfgang Goethe University, 60438 Frankfurt am Main, Germany; Buchmann Institute for Molecular Life Sciences and Structural Genomics Consortium (SGC), 60438 Frankfurt am Main, Germany

Giovanni Settanni - Physics Department, Johannes Gutenberg University, 55099 Mainz, Germany; (1) orcid.org/0000-00031338-937X

Rhiannon N. Jones - Department of Chemistry, School of Life Sciences, University of Sussex, Falmer, Brighton, East Sussex BN1 9QJ, United Kingdom

Xiaomin Ni - Institute of Pharmaceutical Chemistry, Johann Wolfgang Goethe University, 60438 Frankfurt am Main, Germany; Buchmann Institute for Molecular Life Sciences and Structural Genomics Consortium (SGC), 60438 Frankfurt am Main, Germany

Raysa Khan Tareque - Department of Chemistry, School of Life Sciences, University of Sussex, Falmer, Brighton, East Sussex BN1 9QJ, United Kingdom

Alan R. Fersht - MRC Laboratory of Molecular Biology, Cambridge CB2 OQH, United Kingdom

John Spencer - Department of Chemistry, School of Life Sciences, University of Sussex, Falmer, Brighton, East Sussex BN1 9QJ, United Kingdom; 이이.org/0000-0001-52318836

Complete contact information is available at: https://pubs.acs.org/10.1021/acschembio.9b00748

\section{Author Contributions}

\#These authors contributed equally

Notes

The authors declare no competing financial interest.

\section{ACKNOWLEDGMENTS}

This work was funded by German Research Foundation (DFG) grant JO 1473/1-1 (A.C.J.) and Worldwide Cancer Research (grants 14-1002, 18-0043). G.S. is funded by the DFG grant SFB1066 project Q1 and acknowledges support from the Max-Planck Graduate Center with the University of Mainz. We gratefully acknowledge support with computing time from the HPC facility Hazelhen at the High Performance Computing Center Stuttgart (project Flexadfg) and the HPC facility Mogon at the University of Mainz. We are grateful for support by the SGC, a registered charity (number 1097737) that receives funds from AbbVie, Bayer Pharma AG, Boehringer Ingelheim, Canada Foundation for Innovation, Eshelman Institute for Innovation, Genome Canada through Ontario Genomics Institute, Innovative Medicines Initiative (EU/EFPIA; ULTRA-DD grant no. 115766), Janssen, Merck \& Co., Novartis Pharma AG, Ontario Ministry of Economic Development and Innovation, Pfizer, São Paulo Research Foundation-FAPESP, Takeda, and the Wellcome Trust. We also thank the staff at beamline I03 of the Diamond Light Source, Oxford, UK and beamline X06SA of the Swiss Light Source, Villigen, Switzerland for their assistance during data collection. We thank L. Holtkamp and S. Truong for help with protein purification and setting up crystallization trials.

\section{REFERENCES}

(1) Joerger, A. C., and Fersht, A. R. (2016) The p53 Pathway: Origins, Inactivation in Cancer, and Emerging Therapeutic Approaches. Annu. Rev. Biochem. 85, 375-404.

(2) Khoo, K. H., Verma, C. S., and Lane, D. P. (2014) Drugging the p53 pathway: understanding the route to clinical efficacy. Nat. Rev. Drug Discovery 13, 217-236.

(3) Stiewe, T., and Haran, T. E. (2018) How mutations shape p53 interactions with the genome to promote tumorigenesis and drug resistance. Drug Resist. Updates 38, 27-43.

(4) Joerger, A. C., and Fersht, A. R. (2007) Structure-functionrescue: the diverse nature of common p53 cancer mutants. Oncogene 26, 2226-2242.

(5) Freed-Pastor, W. A., and Prives, C. (2012) Mutant p53: one name, many proteins. Genes Dev. 26, 1268-1286.

(6) Hainaut, P., and Pfeifer, G. P. (2016) Somatic TP53 Mutations in the Era of Genome Sequencing. Cold Spring Harbor Perspect. Med. 6 , a026179.

(7) Bullock, A. N., Henckel, J., and Fersht, A. R. (2000) Quantitative analysis of residual folding and DNA binding in mutant p53 core domain: definition of mutant states for rescue in cancer therapy. Oncogene 19, 1245-1256.

(8) Wang, G., and Fersht, A. R. (2017) Multisite aggregation of p53 and implications for drug rescue. Proc. Natl. Acad. Sci. U. S. A. 114 E2634-E2643.

(9) Dearth, L. R., Qian, H., Wang, T., Baroni, T. E., Zeng, J., Chen, S. W., Yi, S. Y., and Brachmann, R. K. (2007) Inactive full-length p53 mutants lacking dominant wild-type p53 inhibition highlight loss of heterozygosity as an important aspect of p53 status in human cancers. Carcinogenesis 28, 289-298.

(10) Joerger, A. C., Ang, H. C., and Fersht, A. R. (2006) Structural basis for understanding oncogenic p53 mutations and designing rescue drugs. Proc. Natl. Acad. Sci. U. S. A. 103, 15056-15061. 
(11) Boeckler, F. M., Joerger, A. C., Jaggi, G., Rutherford, T. J., Veprintsev, D. B., and Fersht, A. R. (2008) Targeted rescue of a destabilized mutant of p53 by an in silico screened drug. Proc. Natl. Acad. Sci. U. S. A. 105, 10360-10365.

(12) Wilcken, R., Liu, X., Zimmermann, M. O., Rutherford, T. J., Fersht, A. R., Joerger, A. C., and Boeckler, F. M. (2012) Halogenenriched fragment libraries as leads for drug rescue of mutant p53. J. Am. Chem. Soc. 134, 6810-6818.

(13) Joerger, A. C., Bauer, M. R., Wilcken, R., Baud, M. G., Harbrecht, H., Exner, T. E., Boeckler, F. M., Spencer, J., and Fersht, A. R. (2015) Exploiting Transient Protein States for the Design of SmallMolecule Stabilizers of Mutant p53. Structure 23, 2246-2255.

(14) Bauer, M. R., Jones, R. N., Baud, M. G., Wilcken, R., Boeckler, F. M., Fersht, A. R., Joerger, A. C., and Spencer, J. (2016) Harnessing Fluorine-Sulfur Contacts and Multipolar Interactions for the Design of p53 Mutant Y220C Rescue Drugs. ACS Chem. Biol. 11, 22652274.

(15) Basse, N., Kaar, J. L., Settanni, G., Joerger, A. C., Rutherford, T. J., and Fersht, A. R. (2010) Toward the rational design of p53stabilizing drugs: probing the surface of the oncogenic Y220C mutant. Chem. Biol. 17, 46-56.

(16) Wilcken, R., Wang, G., Boeckler, F. M., and Fersht, A. R. (2012) Kinetic mechanism of p53 oncogenic mutant aggregation and its inhibition. Proc. Natl. Acad. Sci. U. S. A. 109, 13584-13589.

(17) Bauer, M. R., Jones, R. N., Tareque, R. K., Springett, B., Dingler, F. A., Verduci, L., Patel, K. J., Fersht, A. R., Joerger, A. C., and Spencer, J. (2019) A structure-guided molecular chaperone approach for restoring the transcriptional activity of the p53 cancer mutant Y220C. Future Med. Chem. 11, 2491-2504.

(18) Liu, X., Wilcken, R., Joerger, A. C., Chuckowree, I. S., Amin, J., Spencer, J., and Fersht, A. R. (2013) Small molecule induced reactivation of mutant p53 in cancer cells. Nucleic Acids Res. 41, 6034-6044.

(19) Baud, M. G. J., Bauer, M. R., Verduci, L., Dingler, F. A., Patel, K. J., Horil Roy, D., Joerger, A. C., and Fersht, A. R. (2018) Aminobenzothiazole derivatives stabilize the thermolabile p53 cancer mutant Y220C and show anticancer activity in p53-Y220C cell lines. Eur. J. Med. Chem. 152, 101-114.

(20) Wassman, C. D., Baronio, R., Demir, O., Wallentine, B. D., Chen, C.-K., Hall, L. V., Salehi, F., Lin, D.-W., Chung, B. P., Wesley Hatfield, G., Richard Chamberlin, A., Luecke, H., Lathrop, R. H., Kaiser, P., and Amaro, R. E. (2013) Computational identification of a transiently open L1/S3 pocket for reactivation of mutant p53. Nat. Commun. 4, 1407.

(21) Pradhan, M. R., Siau, J. W., Kannan, S., Nguyen, M. N., Ouaray, Z., Kwoh, C. K., Lane, D. P., Ghadessy, F., and Verma, C. S. (2019) Simulations of mutant p53 DNA binding domains reveal a novel druggable pocket. Nucleic Acids Res. 47, 1637-1652.

(22) Lambert, J. M., Gorzov, P., Veprintsev, D. B., Soderqvist, M., Segerback, D., Bergman, J., Fersht, A. R., Hainaut, P., Wiman, K. G., and Bykov, V. J. (2009) PRIMA-1 reactivates mutant p53 by covalent binding to the core domain. Cancer Cell 15, 376-388.

(23) Bykov, V. J., Zhang, Q., Zhang, M., Ceder, S., Abrahmsen, L., and Wiman, K. G. (2016) Targeting of Mutant p53 and the Cellular Redox Balance by APR-246 as a Strategy for Efficient Cancer Therapy. Front. Oncol. 6, 21.

(24) Bauer, M. R., Joerger, A. C., and Fersht, A. R. (2016) 2Sulfonylpyrimidines: Mild alkylating agents with anticancer activity toward p53-compromised cells. Proc. Natl. Acad. Sci. U. S. A. 113, E5271-5280.

(25) Blanden, A. R., Yu, X., Wolfe, A. J., Gilleran, J. A., Augeri, D. J., O’Dell, R. S., Olson, E. C., Kimball, S. D., Emge, T. J., Movileanu, L., Carpizo, D. R., and Loh, S. N. (2015) Synthetic Metallochaperone ZMC1 Rescues Mutant p53 Conformation by Transporting Zinc into Cells as an Ionophore. Mol. Pharmacol. 87, 825-831.

(26) Bouaoun, L., Sonkin, D., Ardin, M., Hollstein, M., Byrnes, G., Zavadil, J., and Olivier, M. (2016) TP53 Variations in Human Cancers: New Lessons from the IARC TP53 Database and Genomics Data. Hum. Mutat. 37, 865-876.
(27) Leroy, B., Fournier, J. L., Ishioka, C., Monti, P., Inga, A., Fronza, G., and Soussi, T. (2013) The TP53 website: an integrative resource centre for the TP53 mutation database and TP53 mutant analysis. Nucleic Acids Res. 41, D962-969.

(28) Bray, F., Ferlay, J., Soerjomataram, I., Siegel, R. L., Torre, L. A., and Jemal, A. (2018) Global cancer statistics 2018: GLOBOCAN estimates of incidence and mortality worldwide for 36 cancers in 185 countries. Ca-Cancer J. Clin. 68, 394-424.

(29) Capponcelli, S., Pedrini, E., Cerone, M. A., Corti, V., Fontanesi, S., Alessio, M., Bachi, A., Soddu, S., Ribatti, D., Picci, P., Helman, L. J., Cantelli-Forti, G., and Sangiorgi, L. (2005) Evaluation of the molecular mechanisms involved in the gain of function of a LiFraumeni TP53 mutation. Hum. Mutat. 26, 94-103.

(30) Nikolova, P. V., Henckel, J., Lane, D. P., and Fersht, A. R. (1998) Semirational design of active tumor suppressor p53 DNA binding domain with enhanced stability. Proc. Natl. Acad. Sci. U. S. A. 95, 14675-14680.

(31) Joerger, A. C., Allen, M. D., and Fersht, A. R. (2004) Crystal structure of a superstable mutant of human p53 core domain. Insights into the mechanism of rescuing oncogenic mutations. J. Biol. Chem. 279, 1291-1296.

(32) Ang, H. C., Joerger, A. C., Mayer, S., and Fersht, A. R. (2006) Effects of common cancer mutations on stability and DNA binding of full-length p53 compared with isolated core domains. J. Biol. Chem. 281, 21934-21941.

(33) Bienert, S., Waterhouse, A., de Beer, T. A., Tauriello, G., Studer, G., Bordoli, L., and Schwede, T. (2017) The SWISS-MODEL Repository-new features and functionality. Nucleic Acids Res. 45, D313-D319.

(34) Interlandi, G., Wetzel, S. K., Settanni, G., Pluckthun, A., and Caflisch, A. (2008) Characterization and further stabilization of designed ankyrin repeat proteins by combining molecular dynamics simulations and experiments. J. Mol. Biol. 375, 837-854.

(35) Bissantz, C., Kuhn, B., and Stahl, M. (2010) A medicinal chemist's guide to molecular interactions. J. Med. Chem. 53, 50615084.

(36) Raghavan, V., Agrahari, M., and Gowda, D. K. (2019) Virtual screening of p53 mutants reveals Y220S as an additional rescue drug target for PhiKan083 with higher binding characteristics. Comput. Biol. Chem. 80, 398-408.

(37) Joerger, A. C., Ang, H. C., Veprintsev, D. B., Blair, C. M., and Fersht, A. R. (2005) Structures of p53 cancer mutants and mechanism of rescue by second-site suppressor mutations. J. Biol. Chem. 280, 16030-16037.

(38) Kabsch, W. (2010) Xds. Acta Crystallogr., Sect. D: Biol. Crystallogr. 66, 125-132.

(39) Evans, P. (2006) Scaling and assessment of data quality. Acta Crystallogr., Sect. D: Biol. Crystallogr. 62, 72-82.

(40) Evans, P. R. (2011) An introduction to data reduction: spacegroup determination, scaling and intensity statistics. Acta Crystallogr., Sect. D: Biol. Crystallogr. 67, 282-292.

(41) Winn, M. D., Ballard, C. C., Cowtan, K. D., Dodson, E. J., Emsley, P., Evans, P. R., Keegan, R. M., Krissinel, E. B., Leslie, A. G., McCoy, A., McNicholas, S. J., Murshudov, G. N., Pannu, N. S., Potterton, E. A., Powell, H. R., Read, R. J., Vagin, A., and Wilson, K. S. (2011) Overview of the CCP4 suite and current developments. Acta Crystallogr., Sect. D: Biol. Crystallogr. 67, 235-242.

(42) Adams, P. D., Afonine, P. V., Bunkoczi, G., Chen, V. B., Davis, I. W., Echols, N., Headd, J. J., Hung, L. W., Kapral, G. J., GrosseKunstleve, R. W., McCoy, A. J., Moriarty, N. W., Oeffner, R., Read, R. J., Richardson, D. C., Richardson, J. S., Terwilliger, T. C., and Zwart, P. H. (2010) PHENIX: a comprehensive Python-based system for macromolecular structure solution. Acta Crystallogr., Sect. D: Biol. Crystallogr. 66, 213-221.

(43) Emsley, P., Lohkamp, B., Scott, W. G., and Cowtan, K. (2010) Features and development of Coot. Acta Crystallogr., Sect. D: Biol. Crystallogr. 66, 486-501. 
(44) Jorgensen, W. L., Chandrasekhar, J., Madura, J. D., Impey, R. W., and Klein, M. L. (1983) Comparison of simple potential functions for simulating liquid water. J. Chem. Phys. 79, 926-935.

(45) Huang, J., Rauscher, S., Nawrocki, G., Ran, T., Feig, M., de Groot, B. L., Grubmuller, H., and MacKerell, A. D., Jr. (2017) CHARMM36m: an improved force field for folded and intrinsically disordered proteins. Nat. Methods 14, 71-73.

(46) Abraham, M. J., Murtola, T., Schulz, R., Páll, S., Smith, J. C., Hess, B., and Lindahl, E. (2015) GROMACS: High performance molecular simulations through multi-level parallelism from laptops to supercomputers. SoftwareX 1, 19-25.

(47) Budiman, M. E., Knaggs, M. H., Fetrow, J. S., and Alexander, R. W. (2007) Using molecular dynamics to map interaction networks in an aminoacyl-tRNA synthetase. Proteins: Struct., Funct., Genet. 68, $670-689$.

(48) Godwin, R. C., Melvin, R. L., Gmeiner, W. H., and Salsbury, F. R., Jr. (2017) Binding Site Configurations Probe the Structure and Dynamics of the Zinc Finger of NEMO (NF-kappaB Essential Modulator). Biochemistry 56, 623-633.

(49) Nosé, S. (1984) A unified formulation of the constant temperature molecular dynamics methods. J. Chem. Phys. 81, 511519.

(50) Hoover, W. G. (1985) Canonical dynamics: Equilibrium phasespace distributions. Phys. Rev. A: At., Mol., Opt. Phys. 31, 1695-1697.

(51) Parrinello, M., and Rahman, A. (1980) Crystal Structure and Pair Potentials: A Molecular-Dynamics Study. Phys. Rev. Lett. 45, 1196-1199.

(52) Essmann, U., Perera, L., Berkowitz, M. L., Darden, T., Lee, H., and Pedersen, L. G. (1995) A smooth particle mesh Ewald method. J. Chem. Phys. 103, 8577-8592.

(53) Hess, B., Bekker, H., Berendsen, H. J. C., and Fraaije, J. G. E. M. (1997) LINCS: A linear constraint solver for molecular simulations. J. Comput. Chem. 18, 1463-1472.

(54) Humphrey, W., Dalke, A., and Schulten, K. (1996) VMD: visual molecular dynamics. J. Mol. Graphics 14, 33-38.

(55) Seeber, M., Cecchini, M., Rao, F., Settanni, G., and Caflisch, A. (2007) Wordom: a program for efficient analysis of molecular dynamics simulations. Bioinformatics 23, 2625-2627.

(56) Vanommeslaeghe, K., Hatcher, E., Acharya, C., Kundu, S., Zhong, S., Shim, J., Darian, E., Guvench, O., Lopes, P., Vorobyov, I., and Mackerell, A. D., Jr. (2009) CHARMM general force field: A force field for drug-like molecules compatible with the CHARMM allatom additive biological force fields. J. Comput. Chem. 31, 671-690.

(57) Brandt, T., Kaar, J. L., Fersht, A. R., and Veprintsev, D. B.

(2012) Stability of p53 homologs. PLoS One 7, e47889. 